\title{
Zinc Transporter 3 (Znt3) as an Active Substance in the Enteric Nervous System of the Porcine Esophagus
}

\author{
Joanna Wojtkiewicz $^{1} \cdot$ Krystyna Makowska $^{2} \cdot$ Ewa Bejer-Olenska $^{1}$. \\ Sławomir Gonkowski ${ }^{2}$
}

Received: 1 August 2016/Accepted: 21 October 2016/Published online: 30 October 2016

(C) The Author(s) 2016. This article is published with open access at Springerlink.com

\begin{abstract}
Zinc transporter 3 (ZnT3), a member of the SLC 30 zinc transporter family, is involved in the transport of zinc ions from the cytoplasm into synaptic vesicles or intracellular organelles. The aim of the present study was to investigate for the first time the percentage of ZnT3-like immunoreactive (ZnT3-LI) neurons in the enteric nervous system (ENS) of the porcine esophagus and denotation of their neurochemical coding. Routine double- and triple-immunofluorescence labeling of cervical, thoracic, and abdominal fragments of esophagus for ZnT3 with protein gene product (PGP 9.5; used as pan-neuronal marker), nitric oxide synthase (NOS), somatostatin, vasoactive intestinal peptide (VIP), vesicular acetylcholine transporter (VAChT), neuropeptide Y (NPY), and galanin (GAL) was performed. The percentage of ZnT3-LI neurons in myenteric ganglia amounted to $50.2 \pm 4.7$, $63.4 \pm 8.3$, and $77.1 \pm 1.1 \%$ of all PGP 9.5-like immunoreactive neuronal cells in cervical, thoracic, and abdominal esophagus, respectively. In submucous ganglia, these values in particular parts of esophagus amounted to $46.3 \pm 6.3$, $81.0 \pm 8.1$, and $74.4 \pm 4.4 \%$. Znt3 co-localized mainly with VAChT, NPY, GAL, NOS, and VIP, but the degree of colocalization depended on the "kind" of enteric ganglia and part of esophagus studied. The obtained results suggest that both ZnT3 and zinc ions may play important and various roles in the neuronal regulation of esophageal functions.
\end{abstract}

Joanna Wojtkiewicz

joanna.wojtkiewicz@uwm.edu.pl

1 Department of Pathophysiology, Faculty of Medical Sciences, Warszawska Str. 30, 10-082 Olsztyn, Poland

2 Department of Clinical Physiology, Faculty of Veterinary Medicine, University of Warmia and Mazury, Oczapowskiego Str. 13, 10-718 Olsztyn, Poland
Keywords Zinc transporters · Esophagus · Enteric nervous system

\section{Introduction}

The enteric nervous system (ENS) is made up of millions of neuronal cells located in the wall of the gastrointestinal (GI) tract from esophagus to anus (Furness et al. 2014). Its organization depends on animal species and the part of the GI tract (Timmermans et al. 1997; Brown and Timmermans 2004). In esophagus and stomach, the ENS consists of the following two kinds of intramural ganglia: myenteric ganglia (MG), which are connected to each other by density network of nerves and create myenteric plexus located between the longitudinal and circular muscle layers, as well as submucous ganglia (SG), which not form a plexus and situated near the lamina propria of the mucosal layer (Teixeira et al. 2001; Zacharko-Siembida and Arciszewski 2014; Chiocchetti et al. 2015; Rekawek et al. 2015). The same types of enteric ganglia are present in small and large intestine of rodents, but contrary to esophagus and stomach, also submucous ganglia form plexus (Paulino et al. 2011). In small and large intestine of big mammals (for example in pig), submucous plexus is divided into outer submucous plexus located near internal side of the circular muscle layer and inner submucous plexus - between the muscularis mucosa and lamina propria (Brown and Timmermans 2004; Gonkowski et al. 2009a, 2012a).

In spite of the fact that ENS receives signals from extrinsic parasympathetic and sympathetic nervous structures (Wojtkiewicz et al. 2013), it is characterized by significant autonomy and able to fully function in the absence of central input. The ENS takes part in the regulation of all functions of the GI tract, such as intestinal motility, excretive activity of the mucosal layer, fluid exchange between the wall of stomach 
and gut and their lumen, and local blood flow (Furness et al. 2014). Moreover, it is known that enteric neurons can also play important functions under various pathological stimuli and take part in adaptive, regenerative, and/or neuroprotective processes during intestinal and extra-intestinal diseases (Gonkowski et al. 2003; Vasina et al. 2006; Gonkowski 2013).

All above-mentioned functions of the ENS are realized with a range spectrum of neuronal active substances, which most often can play roles of neuromediators and/or neuromodulators. Several dozen such substances have been described in neuronal cells and nerves within the ENS. Besides acetylcholine - typical neuromediator for parasympathetic nervous system, also other active substances have been described within enteric neurons. The most important of these substances include vasoactive intestinal polypeptide (VIP), somatostatin (SOM), substance P (SP), pituitary adenylate cyclase-activating peptide (PACAP), nitric oxide (NO), galanin (GAL), and many others (Vasina et al. 2006; Furness et al. 2014). One of substances which functions within the enteric nervous system remain still obscure is zinc transporter 3 (ZnT3) (Wojtkiewicz et al. 2012a, b).

ZnT3 is a member of SLC 30 family zinc transporters, which enable the transport of hydrophilic zinc ions from the cytoplasm into synaptic vesicles, intracellular organelles, or to the outside of the cell. Ten members of $\mathrm{ZnT}$ peptide family (marked by abbreviation ZnT1-ZnT10) have been identified in various tissues of mammals (Palmiter and Huang 2004). All these transporters are constructed of six transmembrane domains and loop of amino acid chain rich in histidine, which is the place zinc ions bind. In all $\mathrm{ZnT}$ transporters, only $\mathrm{ZnT} 3$ is closely associated with neuronal cells, which takes part in conduction of impulses by the transport of zinc ions to synaptic vesicle (Palmiter et al. 1996), although the newest studies describe the presence of $\mathrm{ZnT} 3$ also in pancreatic beta cells (Smidt et al. 2016).

ZnT3 has been described in different regions of the central and peripheral nervous system (Wenzel et al. 1997; Wang et al. 2002, 2005; Kaneko et al. 2015). First of all, Znt3 is considered to be a marker of zinc-enriched (ZEN) terminals within brain, spinal cord, and superior cervical ganglion (Jo et al. 2000; Wenzel et al. 1997). These nerves, and indeed ZnT3, show inhibitory effects and take part in sensory conduction and excretive function, as well as play some, not fully explained, roles during pathological processes, such as epilepsy, cerebral ischemia, and amyotrophic lateral sclerosis (Takeda 2000; Danscher et al. 2001; Molnar and Nadler 2001; Kaneko et al. 2015).

ZnT3 has been also observed in the ENS, but it should be pointed out that the knowledge about distribution of ZnT3 in this part of nervous system is very scanty. Namely, this substance has been described in human large and porcine small intestine, and its functions in neuronal processes within the GI tract are completely unknown (Gonkowski et al. 2009b;
Wojtkiewicz et al. 2012a, b). So, the present study describes for the first time the localization and chemical coding of ZnT3-like immunoreactive neurons within the enteric nervous system of porcine esophagus and may be the introduction for further investigations on exact functions of $\mathrm{Znt} 3$ within the digestive system.

\section{Materials and Methods}

The present investigation was performed on six immature female pigs of the Large White Polish breed (approximately 8 weeks old). Animals were kept under standard laboratory conditions, and all experimental procedures were made following the instructions of the Local Ethical Committee in Olsztyn (Poland), with special attention paid to minimizing any stress reaction during investigation.

After adaptive period in laboratory ( 3 days), animals were pre-treated with Stressnil (Janssen, Belgium, $75 \mu \mathrm{l} /$ $\mathrm{kg}$ of body weight, i.m.) $15 \mathrm{~min}$ before the euthanasia by an overdose of sodium thiopental (Thiopental, Sandoz, Kundl-Rakúsko, Austria) given intravenously. Then, pigs were perfused transcardially with $4 \%$ buffered paraformaldehyde prepared ex tempore. The selfsame parts (ca. $1 \mathrm{~cm}$ long) of cervical, thoracic, and abdominal esophagus were collected from all animals studied; post-fixed by immersion in the same fixative for $30 \mathrm{~min}$; rinsed in phosphate buffer for several hours; stored in $18 \%$ sucrose until sectioning (at least 10 days); and finally, cut into 10 - $\mu \mathrm{m}$-thick cryostat sections. These sections were subjected to standard double- and triple-labeling immunofluorescence as described previously by Gonkowski et al. (2012b) and Wojtkiewicz et al. (2012a). In essence, the immunofluorescence procedure has been made as follows: after air-drying at room temperature (RT) for $45 \mathrm{~min}$, sections of esophagus were incubated with a blocking solution containing $10 \%$ normal goat serum, $0.1 \%$ bovine serum albumin, $0.01 \% \mathrm{NaN} 3$, Triton $\mathrm{X}-100$, and thimerozal in PBS for $1 \mathrm{~h}$ (RT). Then, they were incubated (overnight; RT, in a humid chamber) with a mixture of two (in double-immunofluorescence technique) or three (in triple-immunofluorescence technique) antibodies raised in different species and directed towards zinc transporter 3 and one of the other selected neuronal active substance, i.e., protein gene product 9.5 (PGP 9.5; used here as pan-neuronal marker), vesicular acetylcholine transporter (VAChT; used here as marker of cholinergic neurons), neuropeptide Y (NPY), vasoactive intestinal polypeptide (VIP), somatostatin (SOM), galanin (GAL), or nitric oxide synthase (NOS) - a marker of nitrergic processes, raised in different species (the precise specification of anti-sera is presented in Table 1). Complexes of primary antibodies bound to appropriate antigens were 
Table 1 Specification of immune reagents vs. zinc transporter 3

\begin{tabular}{|c|c|c|c|c|}
\hline \multicolumn{5}{|c|}{ Primary antibody } \\
\hline Antisera & Code & Host species & Dilution & Supplier \\
\hline PGP 9.5 & $7863-2004$ & Mouse & $1: 2000$ & Biogenesis Inc., UK; www.biogenesis.co.uk \\
\hline ZnT3 & - & Rabbit & $1: 600$ & Gift prof. Palmiter, USA \\
\hline GAL & $\mathrm{T}-5036$ & Guinea pig & $1: 1000$ & $\begin{array}{l}\text { Peninsula Labs, USA; see Bachem AG; } \\
\text { www.bachem.com }\end{array}$ \\
\hline NOS & N2280 & Mouse & 1: 2000 & Sigma, USA; www.sigma-aldrich.com \\
\hline NPY & NZ1115 & Rat & $1: 300$ & Biomol Research Laboratories Inc., USA \\
\hline SOM & $8330-0009$ & Rat & 1: 100 & Biogenesis Inc., UK; www.biogenesis.co.uk \\
\hline VAChT & H-V007 & Goat & 1: 2000 & $\begin{array}{l}\text { Phoenix Pharmaceuticals Inc., } \\
\text { USA; www.phoenixpeptide.com }\end{array}$ \\
\hline VIP & $9535-0504$ & Mouse & 1: 2000 & Biogenesis Inc., UK; www.biogenesis.co.uk \\
\hline \multicolumn{5}{|c|}{ Secondary antibodies } \\
\hline \multicolumn{3}{|l|}{ Reagent } & Dilution & Supplier \\
\hline \multicolumn{3}{|c|}{ FITC-conjugated donkey-anti-mouse $\operatorname{IgG}(\mathrm{H}+\mathrm{L})$} & $1: 800$ & Jackson, 715-095-151 \\
\hline \multicolumn{3}{|c|}{ FITC-conjugated donkey-anti-rat $\operatorname{IgG}(\mathrm{H}+\mathrm{L})$} & $1: 800$ & Jackson, 712-095-153 \\
\hline \multicolumn{3}{|c|}{ FITC-conjugated donkey-anti-guinea pig $\operatorname{IgG}(\mathrm{H}+\mathrm{L})$} & $1: 1000$ & Jackson, 706-095-148 \\
\hline \multicolumn{3}{|c|}{ FITC-conjugated donkey-anti-goat $\operatorname{IgG}(\mathrm{H}+\mathrm{L})$} & $1: 1000$ & Jackson, 705-096-147 \\
\hline \multicolumn{3}{|c|}{ Biotinylated goat anti-rabbit immunoglobulins } & $1: 1000$ & DAKO, E 0432 \\
\hline \multicolumn{3}{|c|}{$\begin{array}{l}\text { Biotin-conjugated } \mathrm{F}(a b)^{\prime} \text { fragment of affinity-purified } \\
\text { anti-rabbit } \operatorname{IgG}(\mathrm{H}+\mathrm{L})\end{array}$} & $1: 1000$ & BioTrend, 711-1622 \\
\hline \multicolumn{3}{|c|}{ AMCA-conjugated donkey-anti-mouse $\operatorname{IgG}(\mathrm{H}+\mathrm{L})$} & $1: 50$ & Jackson, 715-155-151 \\
\hline \multicolumn{3}{|c|}{ AMCA-conjugated donkey-anti-rat IgG (H + L) } & $1: 50$ & Jackson, 715-155-153 \\
\hline \multicolumn{3}{|c|}{ AMCA-conjugated donkey-anti-goat $\operatorname{IgG}(\mathrm{H}+\mathrm{L})$} & $1: 50$ & Jackson, 705-156-147 \\
\hline \multicolumn{3}{|c|}{ CY3-conjugated streptavidin } & $1: 9000$ & Jackson, 016-160-084 \\
\hline
\end{tabular}

PGP 9.5 pan-neuronal marker, ZnT3 zinc transporter 3, NOS nitric oxide synthase, VIP vasoactive intestinal peptide, SOM somatostatin, VAChT vesicular acetylcholine transporter, NPY neuropeptide Y, GAL galanin, CGRP calcitonin gene-related peptide, FITC fluorescein isothiocyanate, $A M C A$ 7-amino-4-methylcoumarin-3-acetic acid, $H$ heavy chain, $L$ light chain

visualized by incubation ( $1 \mathrm{~h}$, RT) with species-specific secondary anti-sera conjugated to FITC or biotin, and the latter antibodies were then visualized by a streptavidinCY3 complex (1 h, RT). Each step of immunolabeling was followed by rinsing the sections with PBS $(3 \times 10 \mathrm{~min}, \mathrm{pH}$ 7.4). Standard controls, i.e., preabsorption of the neuropeptide anti-sera with appropriate antigen, omission, and replacement of primary anti-sera by non-immune sera, were performed to test the antibodies and specificity of the method.

To evaluate the percentage of populations ZnT3-like immunoreactive neurons, at least 700 PGP 9.5-labeled cell bodies in myenteric (MG) and submucous ganglia (SG) of esophagus of each studied animal were examined. Moreover, to determine the percentages of co-localization of ZnT3 with other substances studied, at least $500 \mathrm{ZnT3}$-positive cell bodies in particular types of enteric ganglia were examined for immunoreactivity to the particular substances investigated. In these studies, ZnT3-positive neurons were considered as representing $100 \%$ for all combinations. The same method was used to establish the percentage of ZnT3-positive cells with reference to neuronal populations immunoreactive to
GAL, NOS, NPY, SOM, VAChT, and VIP, but in this case, the numbers of cells immunoreactive to particular substances studied were considered as $100 \%$.

Double-labeled perikarya (only neurons with clearly visible nucleus were included) were determined under an Olympus BX51 microscope equipped with epi-fluorescence and appropriate filter sets, pooled, and presented as mean \pm SEM. To prevent double counting of SP-LI neurons, the sections were located at least $100 \mu \mathrm{m}$ apart. All pictures were captured by a digital camera connected to a PC. Statistical analysis was carried out with Student's $t$ test (GraphPad Prism v. 6.0; GraphPad Software Inc., San Diego, CA, USA). The differences were considered statistically significant at $p \leq 0.05$.

\section{Results}

\section{The Number of $\mathrm{ZnT3}^{+}$Neurons in the Porcine Esophagus}

During the present investigation, neuronal cells immunoreactive to ZnT3 were observed in myenteric and submucous 
Table 2 Neurochemical characterization of zinc transporter 3-like immunoreactive $\left(\mathrm{ZnT}^{+}\right)$neurons in the enteric ganglia of the porcine esophagus

\begin{tabular}{|c|c|c|}
\hline & Myenteric ganglia & Submucous ganglia \\
\hline \multicolumn{3}{|l|}{ Cervical esophagus } \\
\hline PGP $9.5^{+} / \mathrm{ZnT}^{+\mathrm{a}}$ & $50.2 \pm 4.7$ & $46.3 \pm 6.3$ \\
\hline $\mathrm{ZnT}^{+} / \mathrm{GAL}^{+}$ & $85.2 \pm 1.8$ & $31.8 \pm 2.6$ \\
\hline $\mathrm{ZnT}^{+} / \mathrm{NOS}^{+}$ & $45.5 \pm 3.7$ & $60.8 \pm 7.9$ \\
\hline $\mathrm{ZnT}^{+} / \mathrm{NPY}^{+}$ & $87.3 \pm 6.0$ & $2.8 \pm 0.6$ \\
\hline $\mathrm{ZnT}^{+} / \mathrm{SOM}^{+}$ & 0 & 0 \\
\hline $\mathrm{ZnT}^{+} / \mathrm{VAChT}^{+}$ & $87.9 \pm 2.7$ & $80.3 \pm 3.0$ \\
\hline $\mathrm{ZnT}^{+} / \mathrm{VIP}^{+}$ & $60.6 \pm 2.0$ & $66.2 \pm 1.8$ \\
\hline \multicolumn{3}{|l|}{ Thoracic esophagus } \\
\hline PGP $9.5^{+} / \mathrm{ZnT}^{+\mathrm{a}}$ & $63.4 \pm 8.3$ & $81.0 \pm 8.1$ \\
\hline $\mathrm{ZnT}^{+} / \mathrm{GAL}^{+}$ & $57.0 \pm 4.2$ & $29.7 \pm 13.0$ \\
\hline $\mathrm{ZnT3}^{+} / \mathrm{NOS}^{+}$ & $62.3 \pm 8.0$ & $30.4 \pm 4.6$ \\
\hline $\mathrm{ZnT3}^{+} / \mathrm{NPY}^{+}$ & $77.7 \pm 7.5$ & $6.0 \pm 3.3$ \\
\hline $\mathrm{ZnT}^{+} / \mathrm{SOM}^{+}$ & 0 & 0 \\
\hline $\mathrm{ZnT}^{+} / \mathrm{VAChT}^{+}$ & $54.9 \pm 3.8$ & $78.0 \pm 10.5$ \\
\hline $\mathrm{ZnT}^{+} / \mathrm{VIP}^{+}$ & $40.4 \pm 1.4$ & $6.3 \pm 1.5$ \\
\hline \multicolumn{3}{|l|}{ Abdominal esophagus } \\
\hline PGP $9.5^{+} / \mathrm{ZnT}^{+\mathrm{a}}$ & $77.7 \pm 1.1$ & $74.4 \pm 4.4$ \\
\hline $\mathrm{ZnT}^{+} / \mathrm{GAL}^{+}$ & $28.8 \pm 2.0$ & $42.8 \pm 5.0$ \\
\hline $\mathrm{ZnT}^{+} / \mathrm{NOS}^{+}$ & $79.0 \pm 6.0$ & $79.0 \pm 5.7$ \\
\hline $\mathrm{ZnT}^{+} / \mathrm{NPY}^{+}$ & $44.9 \pm 8.2$ & $28.8 \pm 3.2$ \\
\hline $\mathrm{ZnT}^{+} / \mathrm{SOM}^{+}$ & 0 & 0 \\
\hline $\mathrm{ZnT}^{+} / \mathrm{VAChT}^{+}$ & $25.1 \pm 5.0$ & $23.23 \pm 1.5$ \\
\hline $\mathrm{ZnT}^{+} / \mathrm{VIP}^{+}$ & $87.2 \pm 7.6$ & $79.3 \pm 8.1$ \\
\hline
\end{tabular}

Note that PGP 9.5 is a pan-neuronal marker that marks all neurons in the tissue, and so, $\mathrm{PGP}^{+} / \mathrm{ZnT}^{+}$cells illustrate the percentage of $\mathrm{ZnT3}$ positive neurons. In case of co-localization of $\mathrm{ZnT} 3$ with other neurochemical factors, ZnT3-positive neurons were considered as representing $100 \%$ for all combinations with other neurotransmitters, and so, all the values presented are percentages (means $\pm \mathrm{SEM}$ ) of $\mathrm{ZnT}^{+}$neurons

${ }^{\text {a }}$ The percentage of ZnT3-positive neurons with reference to all cells immunoreactive to PGP 9.5 (used here as pan-neuronal marker; number of PGP 9.5-positive cells $=100 \%$ )

enteric ganglia within all fragments of porcine esophagus studied (Table 2 and Fig. 1). The number of such cells was relatively considerable in both "kinds" of ganglia and clearly depends on the fragment of esophagus. Within myenteric ganglia of cervical esophagus, the percentage of ZnT3-positive neuronal cells amounted to $50.2 \pm 4.7 \%$ of all PGP 9.5-like immunoreactive neurons. In posterior parts of esophagus, these values were even higher and amounted to $63.4 \pm 8.3$ and $77.1 \pm 1.1 \%$ in thoracic and abdominal esophagus, respectively. Numerous population of ZnT3-positive neuronal cell was also noted in submucous ganglia, where the percentage of these neurons amounted to $46.3 \pm 6.3,81.0 \pm 8.1$, and $74.4 \pm 4.4 \%$ of PGP 9.5-LI cells in cervical, thoracic, and abdominal esophagus, respectively.

\section{The Co-Localization of ZnT3 with Other Active Substances in the ENS of Porcine Esophagus}

A broad spectrum of active substances was noted in ZnT3positive neuronal cells of the esophageal ENS during the present study, and the degree of co-localization of ZnT3 with particular substances depends on both "kind" of enteric ganglion, as well as the fragment of esophagus (Table 2).

\section{Cervical Esophagus}

In myenteric ganglia of cervical esophagus (Fig. 2 (1)), the up to $87.9 \pm 2.7 \%$ of all ZnT3-LI neurons also showed expression of VAChT. Similar percentage of cells immunoreactive to ZnT3were also NPY- and/or GAL-positive $(87.3 \pm 6.0$ and $85.2 \pm 1.8 \%$, respectively). A slightly lower degree of colocalization ZnT3 with VIP and/or NOS was noted. The percentages of such neuronal populations amounted to $60.6 \pm 2.0 \%\left(\mathrm{ZnT}^{+} / \mathrm{VIP}^{+}\right)$and $45.5 \pm 3.7 \%\left(\mathrm{ZnT}^{+} /\right.$ $\left.\mathrm{NOS}^{+}\right)$. In turn, SOM was no observed in $\mathrm{ZnT}^{+}$neurons in myenteric ganglia of cervical porcine esophagus during the present study (Table 2).

In submucous ganglia of cervical esophagus (Fig. 3 (1)), the chemical coding of $\mathrm{Znt3}$-positive neurons differed from those, which noted within myenteric ganglia (Table 2). The greatest differences concerned the co-localization of $\mathrm{ZnT3}$ with NPY, GAL, and/or NOS. In SG, the percentage of $\mathrm{ZnT3}^{+} / \mathrm{NPY}^{+}$and $\mathrm{ZnT}^{+} / \mathrm{GAL}^{+}$cells were lower than in myenteric ganglia, which was particularly visible in the event of NPY. Namely, these values amounted to $2.8 \pm 0.6$ and $31.8 \pm 2.6 \%$, respectively. In turn, the number of neurons simultaneously immunoreactive to Znt3 and NOS was higher than within MG and stood at $60.8 \pm 7.9 \%$. The level of colocalization of ZnT3 with other substances studied in SG was similar to those observed in MG.

\section{Thoracic Esophagus}

In myenteric ganglia of thoracic esophagus (Fig. 2 (2)), the most of ZnT3-positive cells were also immunoreactive to NPY $\left(77.7 \pm 7.5 \%\right.$ of all $\mathrm{ZnT}^{+}$neurons $)$, NOS $(62.3 \pm 8.0 \%)$, and/or GAL $(57.0 \pm 4.2 \%)$. In turn, the degree of co-localization of Znt3 with VAChT and/or VIP was markedly lower than within cervical esophagus and amounted to $54.9 \pm 3.8$ and $40.4 \pm 1.4 \%$, respectively. Within submucous ganglia (Fig. 3 (2)), the number of $\mathrm{ZnT}^{+} / \mathrm{VAChT}^{+}$neuronal cells was higher than in myenteric ganglia and amounted to $78.0 \pm 10.5 \%$ of all neurons immunopositive to ZnT3. Other substances studied were less often observed in ZnT3-like immunoreactive cells. The percentage of $\mathrm{ZnT}^{+} / \mathrm{NOS}^{+}$and $\mathrm{ZnT}^{+} / \mathrm{GAL}^{+}$neurons reached $30.4 \pm 4.6$ and $28.7 \pm 13.0 \%$, respectively. In turn, the number of neurons, in which the co-localization of ZnT3 with VIP and ZnT3 with 
Fig. 1 Representative images of various fragment of the porcine esophagus for PGP9.5 and ZnT3: the cervical part-mesenteric ganglia (MP) $(1 a, 1 b)$, and submucosal ganglia (SG) (1c, 1d); the thoracic part-MP $\left(2 a^{\prime}\right.$, $\left.2 b^{\prime}\right)$ and SG $\left(2 c^{\prime}, 2 d^{\prime}\right)$; and the abdominal part-MP $\left(3 a^{\prime \prime}, 3 b^{\prime \prime}\right)$ and SG $\left(3 c^{\prime \prime}, 3 d^{\prime \prime}\right)$
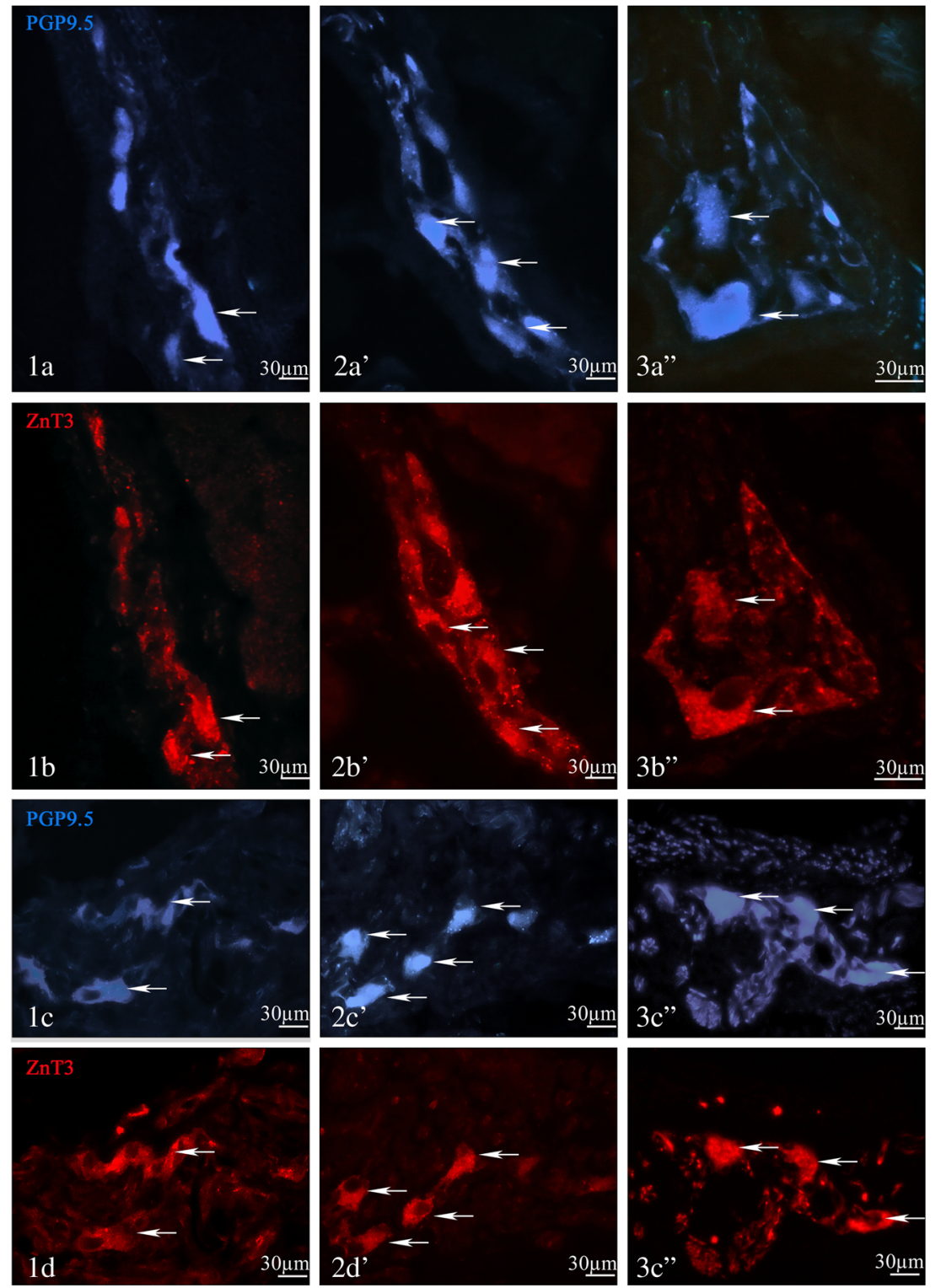

NPY was noted, fluctuated around $6 \%$ of all $\mathrm{ZnT} 3$-LI neurons $(6.3 \pm 1.5$ and $6.0 \pm 3.3 \%$, respectively). Moreover, SOM was no observed in $\mathrm{ZnT} 3$-positive neurons in the neither myenteric nor submucous ganglia of thoracic esophagus.

\section{Abdominal Esophagus}

The most of ZnT3-positive neuronal cells in myenteric ganglia (Fig. 2 (3)) were also immunoreactive to VIP $(87.2 \pm 7.6 \%$ of all $\mathrm{ZnT3}^{+}$neurons) and NOS $(79.0 \pm 6.0 \%)$. A slightly less large population $(44.9 \pm 8.2 \%)$ was cell immunoreactive simultaneously to ZnT3 and NPY. In turn, VAChT and GAL were noted in about a quarter of all $\mathrm{Znt3}$-positive myenteric neurons ( $25.1 \pm 5.0$ and $28.8 \pm 2.0 \%$, respectively).

Within submucous ganglia (Fig. 3 (3)), the degree of colocalization of ZnT3 with NOS and/or VAChT was similar to those, which was observed in myenteric ganglia. These values amounted to $79.0 \pm 5.7$ and $23.23 \pm 1.5 \%$ of all ZnT3-LI neuronal cells. The number of $\mathrm{ZnT}^{+} / \mathrm{VIP}^{+}$and $\mathrm{ZnT}^{+} /$ $\mathrm{NPY}^{+}$was lower than in $\mathrm{MG}(79.3 \pm 8.1$ and $28.8 \pm 3.2 \%$, respectively). The percentage of neurons immunoreactive simultaneously to ZnT3 and GAL amounted to $42.8 \pm 5.0 \%$ of all $\mathrm{ZnT}^{+}$and was higher than the percentage of such type of cells within MG. Moreover, the co-localization of ZnT3 and SOM was no observed in the enteric nervous system of abdominal esophagus (Table 2).

Moreover, $\mathrm{ZnT} 3$-positive perikarya were comprised a large percentage of neurons immunoreactive to the majority of active substances studied, and the biggest degree of colocalization was observed in $\mathrm{VIP}^{+}$neurons in the cervical esophagus, where all cells immunoreactive to VIP were also ZnT3-LI (Table 3). 

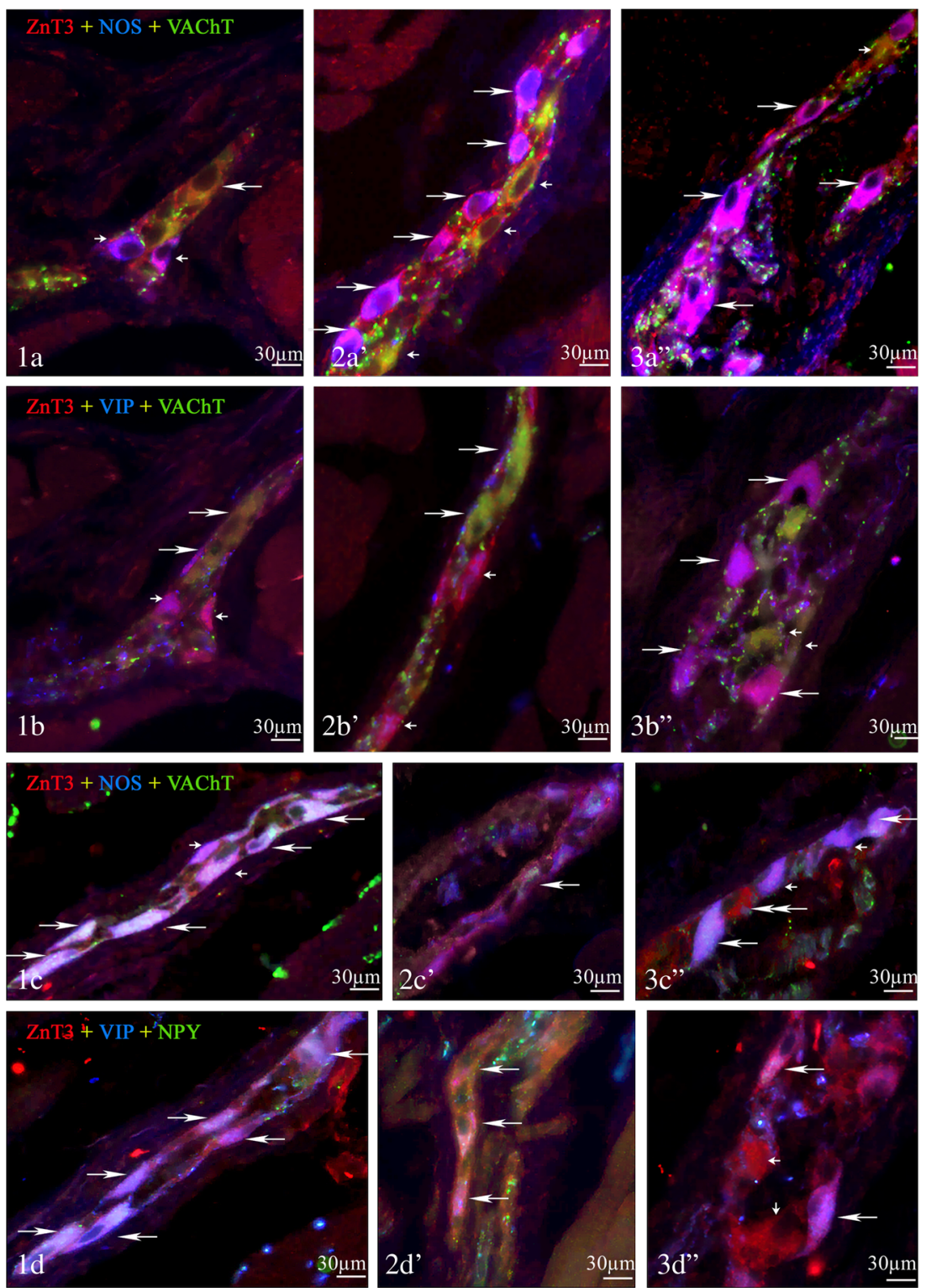

Fig. 2 Representative images of $\mathrm{ZnT}^{+}$neurons located in the various part of porcine esophagus, myenteric ganglia. All images are composites of merged images taken separately from blue, red, and green fluorescent channels. (1) The cervical part- (1a) $\mathrm{ZnT}^{+} / \mathrm{NOS}^{-} / \mathrm{VAChT}^{+}$neuron is indicated with arrow, and $\mathrm{ZnT}^{+} / \mathrm{NOS}^{+} / \mathrm{VAChT}^{-}$neurons are indicated with small arrows; $(1 b) \mathrm{ZnT}^{+} / \mathrm{VIP}^{-} / \mathrm{VAChT}^{+}$neurons are indicated with arrows, and $\mathrm{ZnT}^{+} / \mathrm{VIP}^{+} / \mathrm{VAChT}^{-}$neurons are indicated with small arrows; (1c) $\mathrm{ZnT}^{+} / \mathrm{NOS}^{+} / \mathrm{NPY}^{+}$neurons are indicated with arrows, and $\mathrm{ZnT}^{+} / \mathrm{NOS}^{+} / \mathrm{NPY}^{-}$neurons are indicated with small arrows; and (1d) $\mathrm{ZnT}^{+} / \mathrm{VIP}^{+} / \mathrm{NPY}^{+}$neurons are indicated with arrows. (2) The thoracic part $-\left(2 a^{\prime}\right) \mathrm{ZnT}^{+} / \mathrm{NOS}^{+} / \mathrm{VAChT}^{-}$neurons are indicated with arrows, and $\mathrm{ZnT}^{+} / \mathrm{NOS}^{-} / \mathrm{VAChT}^{+}$neurons are indicated with small arrows; $\left(2 b^{\prime}\right) \mathrm{ZnT}^{+} / \mathrm{VIP}^{+} / \mathrm{VAChT}$ neurons are indicated with arrows,

\section{Discussion}

This experiment for the first time shows the presence of ZnT3LI neurons in the ENS within porcine esophagus, and the large number of such neuronal cells as well as occurrence of them in all types of enteric ganglia strongly suggest important and $\mathrm{ZnT3}^{+} / \mathrm{VIP}^{-} / \mathrm{VAChT}^{-}$neurons are indicated with small arrows; $\left(2 c^{\prime}\right)$ $\mathrm{ZnT}^{+} / \mathrm{NOS}^{-} / \mathrm{NPY}^{+}$neuron is indicated with arrow, and $\mathrm{ZnT}^{+} / \mathrm{NOS}^{+} /$ $\mathrm{NPY}^{-}$neuron is indicated with small arrow; and $\left(2 d^{\prime}\right) \mathrm{ZnT}^{+} / \mathrm{VIP}^{+} / \mathrm{NPY}^{-}$ neurons are indicated with arrows. (3) The abdominal part- $\left(3 a^{\prime \prime}\right)$ $\mathrm{ZnT}^{+} / \mathrm{NOS}^{+} / \mathrm{VAChT}^{-}$neurons are indicated with arrows, and $\mathrm{ZnT}^{+} /$ $\mathrm{NOS}^{-} / \mathrm{VAChT}^{+}$neuron is indicated with small head; $\left(3 b^{\prime \prime}\right) \mathrm{ZnT}^{+} / \mathrm{VIP}^{+} /$ VAChT neurons are indicated with arrows, and $\mathrm{ZnT}^{+} / \mathrm{VIP}^{-} / \mathrm{VAChT}^{+}$ neurons are indicated with small arrows; $\left(3 c^{\prime \prime}\right) \mathrm{ZnT}^{+} / \mathrm{NOS}^{+} / \mathrm{NPY}^{+}$ neurons are indicated with arrows, $\mathrm{ZnT}^{+} / \mathrm{NOS}^{+} / \mathrm{NPY}^{-}$neurons are indicated with small arrows, and $\mathrm{ZnT}^{+} / \mathrm{NOS}^{-} / \mathrm{NPY}^{-}$neuron is indicated with double-headed arrow; and $\left(3 d^{\prime \prime}\right) \mathrm{ZnT}^{+} / \mathrm{VIP}^{+} / \mathrm{NPY}^{+}$ neurons are indicated with arrows, and $\mathrm{ZnT}^{+} / \mathrm{VIP}^{-} / \mathrm{NPY}^{-}$neurons are indicated with small arrows

functions of $\mathrm{ZnT} 3$ in regulatory processes concerning this part of the GI tract. The obtained results are in agreement with previous studies, where numerous $\mathrm{ZnT3}$-positive neurons have been described in other fragments of porcine digestive tract (Wojtkiewicz et al. 2012a, b). Nonetheless, exact functions of ZnT3 in the enteric nervous system remain unknown. 

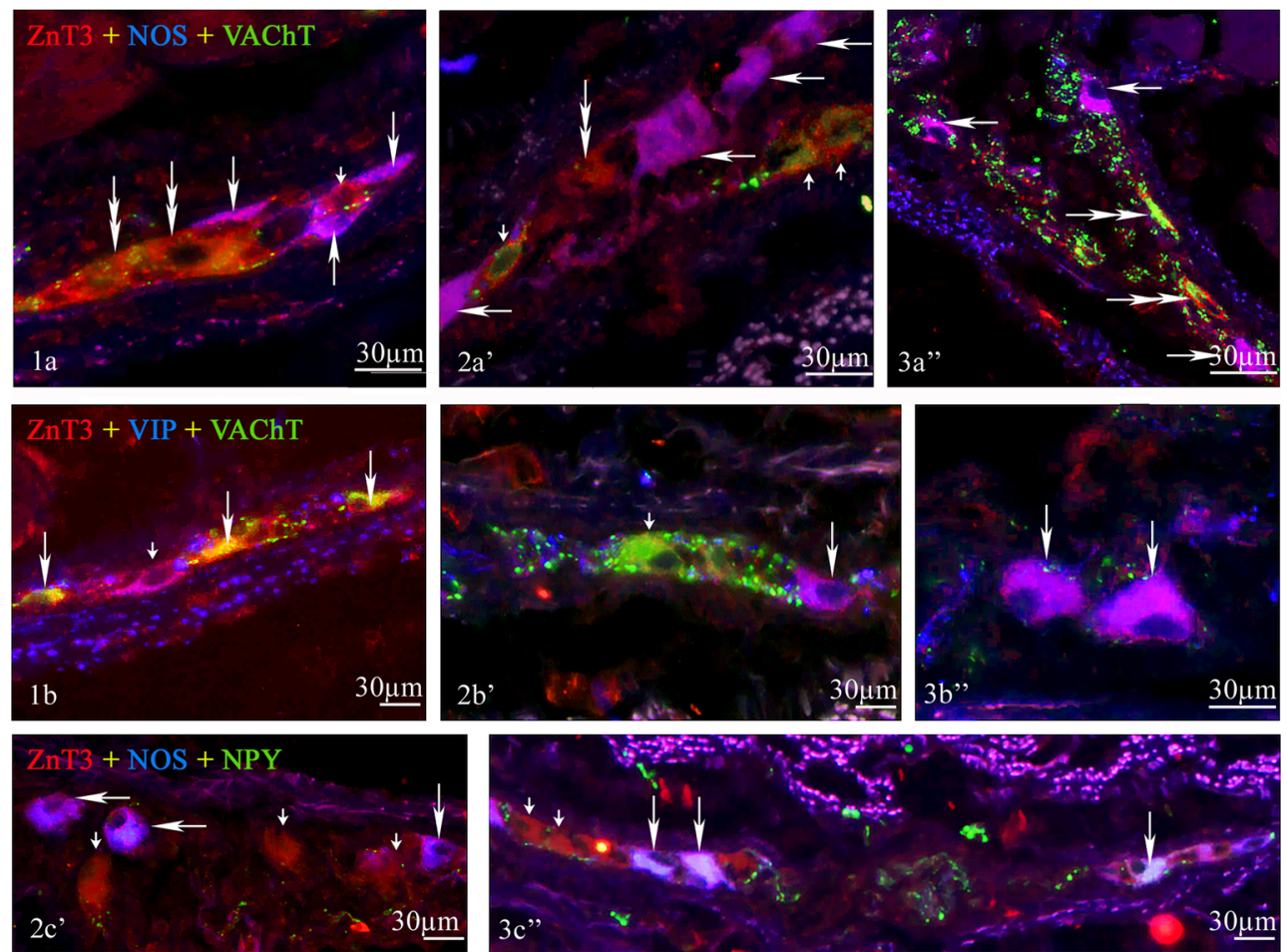
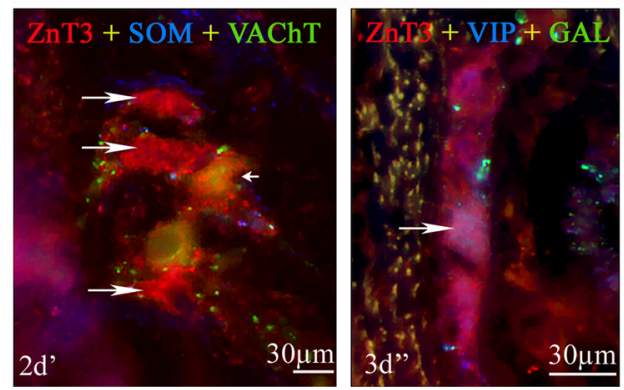

Fig. 3 Representative images of $\mathrm{ZnT}^{+}$neurons located in the various part of porcine esophagus, submucous ganglia. All images are composites of merged images taken separately from blue, red, and green fluorescent channels. (1) The cervical part - (1a) $\mathrm{ZnT}^{+} / \mathrm{NOS}^{+} / \mathrm{VAChT}^{-}$neurons are indicated with arrows, $\mathrm{ZnT}^{+} / \mathrm{NOS}^{-} / \mathrm{VAChT}^{+}$cells are indicated with small arrows, and $\mathrm{ZnT}^{+} / \mathrm{NOS}^{-} / \mathrm{VAChT}^{-}$neuron is indicated with double-headed arrow and $(1 b) \mathrm{ZnT}^{+} / \mathrm{VIP}^{-} / \mathrm{VAChT}^{+}$neurons are indicated with arrows, and $\mathrm{ZnT}^{+} / \mathrm{VIP}^{+} / \mathrm{VAChT}^{-}$neuron is indicated with small arrow. (2) The thoracic part- $\left(2 a^{\prime}\right) \mathrm{ZnT}^{+} / \mathrm{NOS}^{+} / \mathrm{VAChT}^{-}$ neurons are indicated with arrows, $\mathrm{ZnT}^{+} / \mathrm{NOS}^{-} / \mathrm{VAChT}^{+}$neurons are indicated with small arrows, and $\mathrm{ZnT}^{+} / \mathrm{NOS}^{-} / \mathrm{VAChT}^{-}$neuron is indicated with double-headed arrow; $\left(2 b^{\prime}\right) \mathrm{ZnT}^{+} / \mathrm{VIP}^{+} / \mathrm{VAChT}^{-}$ neuron is indicated with arrow, and $\mathrm{ZnT}^{+} / \mathrm{VIP}^{-} / \mathrm{VAChT}^{+}$neuron is indicated with small arrow; $\left(2 c^{\prime}\right) \mathrm{ZnT}^{+} / \mathrm{NOS}^{+} / \mathrm{NPY}^{-}$neurons are indicated with arrows, and $\mathrm{ZnT}^{+} / \mathrm{NOS}^{-} / \mathrm{NPY}^{+}$neurons are indicated

One could only conjecture that these functions can be, at least in part, similar to roles of ZnT3 in the central nervous system, where processes regulated by ZnT3 are better known. Namely, it is well established that $\mathrm{ZnT} 3$ is involved in the regulation of zinc levels in neuronal cells, as well as it takes part in transport of zinc into synaptic vesicles (Palmiter et al. 1996). Previous studies described the participation of ZnT3 in both afferent (sensory) and efferent, especially secretory, conduction

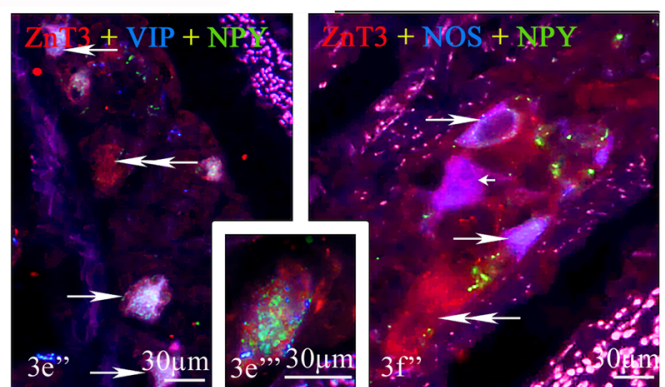

with small arrows; and $\left(3 d^{\prime}\right) \mathrm{ZnT}^{+} / \mathrm{SOM}^{-} / \mathrm{VAChT}^{-}$cells are indicated with arrows, and $\mathrm{ZnT}^{+} / \mathrm{SOM}^{-} / \mathrm{VAChT}^{+}$neuron is indicated with small arrow. (3) The abdominal part- $\left(3 a^{\prime \prime}\right) \mathrm{ZnT}^{+} / \mathrm{NOS}^{+} / \mathrm{VAChT}^{-}$neurons are indicated with arrows, $\mathrm{ZnT}^{+} / \mathrm{NOS}^{-} / \mathrm{VAChT}^{+}$neurons are indicated with small arrows, and $\mathrm{ZnT}^{+} / \mathrm{NOS}^{-} / \mathrm{VAChT}^{-}$neuron is indicated with double-headed arrow; $\left(3 b^{\prime \prime}\right) \mathrm{ZnT}^{+} / \mathrm{VIP}^{+} / \mathrm{VAChT}^{-}$neurons are indicated with arrows; $\left(3 c^{\prime \prime}\right) \mathrm{ZnT}^{+} / \mathrm{NOS}^{+} / \mathrm{NPY}^{+}$neurons are indicated with arrows, $\mathrm{ZnT}^{+} / \mathrm{NOS}^{+} / \mathrm{NPY}^{-}$neuron is indicated with small arrow, and $\mathrm{ZnT}^{+} / \mathrm{NOS}^{-} / \mathrm{NPY}^{-}$is indicated with double-headed arrow; $\left(3 d^{\prime \prime}\right)$ $\mathrm{ZnT}^{+} / \mathrm{VIP}^{+} / \mathrm{GAL}^{+}$neurons are indicated with arrows; $\left(3 e^{\prime \prime}\right) \mathrm{ZnT}^{+} /$ $\mathrm{VIP}^{+} / \mathrm{NPY}^{+}$neurons are indicated with arrows, and $\mathrm{ZnT}^{+} / \mathrm{NOS}^{-} /$ NPY is indicated with double-headed arrow; and $\left(3 f^{\prime \prime}\right) \mathrm{ZnT}^{+} / \mathrm{NOS}^{+} /$ $\mathrm{GAL}^{+}$neurons are indicated with arrows, $\mathrm{ZnT}^{+} / \mathrm{NOS}^{+} / \mathrm{GAL}^{-}$neuron is indicated with small arrow, and $\mathrm{ZnT}^{+} / \mathrm{NOS}^{+} / \mathrm{GAL}^{-}$neuron is indicated with small arrow

(Danscher et al. 2001, 2003). Moreover, ZnT3 is known as substance characteristic of inhibitory zinc-enriched nerves (Wang et al. 2002). Other studies showed that this substance is also involved in pathological processes concerning the central nervous system (Takeda 2000; Molnar and Nadler 2001; Kaneko et al. 2015). Since there is a high degree of colocalization of zinc transporter 3 with active zinc in the same neurons of central and peripheral nervous system, ZnT3 is 
Table 3 The percentage (means \pm SEM) of zinc transporter 3-like immunoreactive $\left(\mathrm{ZnT}^{+}\right)$perikarya in neuronal populations immunoreactive to particular active substances studied

\begin{tabular}{|c|c|c|}
\hline & Myenteric ganglia & Submucous ganglia \\
\hline \multicolumn{3}{|l|}{ Cervical esophagus } \\
\hline $\mathrm{GAL}^{+} / \mathrm{ZnT}^{+}$ & $93.0 \pm 0.2$ & $79.6 \pm 2.5$ \\
\hline $\mathrm{NOS}^{+} / \mathrm{ZnT}^{+}$ & $82.6 \pm 4.9$ & $73.0 \pm 5.2$ \\
\hline $\mathrm{NPY}^{+} / \mathrm{ZnT}^{+}$ & $87.6 \pm 1.3$ & $33.8 \pm 3.4$ \\
\hline $\mathrm{SOM}^{+} / \mathrm{ZnT}^{+}$ & 0 & 0 \\
\hline $\mathrm{VAChT}^{+} / \mathrm{ZnT}^{+}$ & $81.5 \pm 4.1$ & 100 \\
\hline $\mathrm{VIP}^{+} / \mathrm{ZnT}^{+}$ & 100 & 100 \\
\hline \multicolumn{3}{|l|}{ Thoracic esophagus } \\
\hline $\mathrm{GAL}^{+} / \mathrm{ZnT}^{+}$ & $86.0 \pm 6.0$ & $68.0 \pm 13.0$ \\
\hline $\mathrm{NOS}^{+} / \mathrm{ZnT}^{+}$ & $78.0 \pm 4.0$ & $92.0 \pm 4.1$ \\
\hline $\mathrm{NPY}^{+} / \mathrm{ZnT}^{+}$ & $33.3 \pm 5.2$ & $13.13 \pm 6.5$ \\
\hline $\mathrm{SOM}^{+} / \mathrm{ZnT}^{+}$ & 0 & 0 \\
\hline $\mathrm{VAChT}^{+} / \mathrm{ZnT}^{+}$ & $86.1 \pm 4.1$ & $82.9 \pm 11.2$ \\
\hline $\mathrm{VIP}^{+} / \mathrm{ZnT}^{+}$ & $72.0 \pm 4.0$ & $95.0 \pm 3.0$ \\
\hline \multicolumn{3}{|c|}{ Abdominal esophagus } \\
\hline $\mathrm{GAL}^{+} / \mathrm{ZnT}^{+}$ & $91.3 \pm 3.0$ & $90.3 \pm 2.8$ \\
\hline $\mathrm{NOS}^{+} / \mathrm{ZnT}^{+}$ & $88.8 \pm 2.0$ & $95.0 \pm 1.5$ \\
\hline $\mathrm{NPY}^{+} / \mathrm{ZnT}^{+}$ & $95.6 \pm 0.5$ & $97.8 \pm 2.2$ \\
\hline $\mathrm{SOM}^{+} / \mathrm{ZnT}^{+}$ & 0 & 0 \\
\hline $\mathrm{VAChT}^{+} / \mathrm{ZnT}^{+}$ & $80.3 \pm 4.6$ & $88.3 \pm 3.2$ \\
\hline $\mathrm{VIP}^{+} / \mathrm{ZnT}^{+}$ & $77.9 \pm 11.6$ & $87.6 \pm 7.5$ \\
\hline
\end{tabular}

The numbers of neurons immunoreactive to each substance (at least 500 cells in each "kind" of ganglia of each animal) were considered as representing $100 \%$

considered to be a substance typical for neuronal cells, which use zinc as the neuromodulator (Wang et al. 2003).

The co-localization of ZnT3 with a wide range of other neuronal active substances, observed both during the present study and previous observations (Wojtkiewicz et al. 2012a, b), seems to support various functions of $\mathrm{ZnT3}$ in the enteric nervous system. It is known that one neuron can contain even several active substances (Furness 2012; Furness et al. 2014), which can be used in different physiological and/or pathological situations, but most frequently, they play similar roles. So, studies on co-localization of Znt3 with other better known substances can be one of possible ways to know the exact functions of ZnT3 in the enteric nervous system. Generally, in the porcine esophagus, ZnT3-positive neurons are also immunoreactive to VaChT (marker of cholinergic neurons), NPY, GAL, VIP, and NOS (marker of nitrergic neurons), which suggest similar functions of $\mathrm{ZnT} 3$ and abovementioned substances. Therefore, short characteristic of their functions seems to be justified.

Acetylcholine is a main neuromediator in the ENS, which first of all stimulates contraction of longitudinal and circular muscles of the GI tract (Porter et al. 1996, 2002), as well as takes part in regulatory processes connected with intestinal excretive activity (Bader and Diener 2015). Important functions of acetylcholine in physiology of the GI tract are confirmed by its presence in various classes of enteric neuronal cells, such as intrinsic primary afferent neurons, ascending and descending enteric interneurons, motoneurons, and intestinofugal afferent neurons ( $\mathrm{Li}$ and Furness 1998; Dénes and Gábriel 2004; Furness 2012; Chen et al. 2014).

The most of substances observed in ZnT3-positive neurons during the present study such as NPY, VIP, and nitric oxide, in contrast to acetylcholine, are known as strong inhibitory factors impacting on intestinal motility and activity of gut secretion (Nassar et al. 1995; Mourad et al. 2006; Cox 2007; Kasparek et al. 2007). In turn, functions of galanin within the GI tract are not quite clear and depend on animal species and intestinal fragment studied. It is known that GAL shows stimulating influence on the ileal muscles of the rat and pig (Botella et al. 1992), while within the canine pylorus and ileum, it exhibits the relaxatory action (Fox-Threlkeld et al. 1991).

Because the majority of substances observed in ZnT3positive neurons play inhibitory functions within the GI tract, the obtained results may suggest that zinc transporter 3 in the ENS probably first of all participates in muscular relaxation and processes redacting of excretive activity of mucosal layer. It is in accordance with previous observation in the central nervous system, where inhibitory effects of Znt3 are better known (Danscher et al. 2001). On the other hand, the co-localization of ZnT3 with VAChT suggests that this zinc transporter can also impact the cholinergic stimulatory cells.

Moreover, the present study shows clear differences in the number of ZnT3-positive neurons and in their neurochemical profiles between particular kinds of enteric plexuses as well as the fragment of esophagus studied. This fact strongly suggest that exact roles of this zinc transporter, just like in the case of other enteric neuronal active substances and enteric nervous system as a whole (Fox-Threlkeld et al. 1991; Botella et al. 1992; Furness 2008), clearly depend on the fragment of digestive tract.

To sum up, the obtained results show that $\mathrm{ZnT3}$ is widely distributed in the ENS of porcine esophagus and can colocalize with various other active substances. Probably, it is connected with using of zinc ion as a neuromodulatory factor, but the exact roles of $\mathrm{ZnT} 3$ in the enteric nervous system remain not fully explained and require further studies.

Open Access This article is distributed under the terms of the Creative Commons Attribution 4.0 International License (http:// creativecommons.org/licenses/by/4.0/), which permits unrestricted use, distribution, and reproduction in any medium, provided you give appropriate credit to the original author(s) and the source, provide a link to the Creative Commons license, and indicate if changes were made. 


\section{References}

Bader S, Diener M (2015) Novel aspects of cholinergic regulation of colonic ion transport. Pharmacol Res Perspect 3:e0139

Botella A, Delvaux M, Frexinos J, Bueno L (1992) Comparative effects of galanin on isolated smooth muscle cells from ileum in five mammalian species. Life Sci 50:1253-1261

Brown DR, Timmermans JP (2004) Lessons from the porcine enteric nervous system. Neurogastroenterol Motil 16(Suppl 1):50-54

Chen BN, Sharrad DF, Hibberd TJ, Zagorodnyuk VP, Costa M, Brookes SJ (2014) Neurochemical characterization of extrinsic nerves in myenteric ganglia of the guinea pig distal colon. J Comp Neurol 523:742-756

Chiocchetti R, Giancola F, Mazzoni M, Sorteni C, Romagnoli N, Pietra M (2015) Excitatory and inhibitory enteric innervation of horse lower esophageal sphincter. Histochem Cell Biol 143:625-635

Cox HM (2007) Neuropeptide Y receptors; antisecretory control of intestinal epithelial function. Auton Neurosci Bas Clin 133:76-85

Danscher G, Jo SM, Varea E, Wang Z, Cole TB, Schrøder HD (2001) Inhibitory zinc-enriched terminals in mouse spinal cord. Neuroscience 105:941-947

Danscher G, Wang Z, Kim YK, Kim SJ, Sun Y, Jo SM (2003) Immunocytochemical localization of zinc transporter 3 in the ependyma of the mouse spinal cord. Neurosci Lett 342:81-84

Dénes V, Gábriel R (2004) Calbindin-immunopositive cells are cholinergic interneurons in the myenteric plexus of rabbit ileum. Cell Tissue Res 318:465-472

Fox-Threlkeld JET, McDonald TJ, Cipris S, Woskowska Z, Daniel EE (1991) Galanin inhibition of vasoactive intestinal polypeptide release and circular muscle motility in the isolated perfused canine ileum. Gastroenterology 101:1471-1476

Furness JB (2008) The enteric nervous system: normal functions and enteric neuropathies. Neurogastroenterol Motil 20(Suppl 1):32-38

Furness JB (2012) The enteric nervous system and neurogastroenterology. Nat Rev Gastroenterol Hepatol 9:286-294

Furness JB, Callaghan BP, Rivera LR, Cho HJ (2014) The enteric nervous system and gastrointestinal innervation: integrated local and central control. Adv Exp Med Biol 817:39-71

Gonkowski S (2013) Substance P as a neuronal factor in the enteric nervous system of the porcine descending colon in physiological conditions and during selected pathogenic processes. Biofactors 39:542-551

Gonkowski S, Kaminska B, Bossowska A, Korzon M, Landowski P, Majewski M (2003) The influence of experimental Bacteroides fragilis infection on substance $\mathrm{P}$ and somatostatin-immunoreactive neural elements in the porcine ascending colon - a preliminary report. Folia Morphol (Warsz) 62:455-457

Gonkowski S, Burlinski P, Calka J (2009a) Proliferative enteropathy (PE)-induced changes in galanin-like immunoreactivity in the enteric nervous system of the porcine distal colon. Acta Vet - Beograd 59: 321-330

Gonkowski S, Kaminska B, Landowski P, Skobowiat C, Burlinski P, Majewski M, Calka J (2009b) A population of zinc transporter 3like immunoreactive neurons is present in the ganglia of human descending colon. Adv Clin Exp Med 18:243-248

Gonkowski S, Burlinski P, Szwajca P, Calka J (2012a) Changes in cocaine- and amphetamine-regulated transcript-like immunoreactive (CART-LI) nerve structures of the porcine descending colon during proliferative enteropathy. Bull Vet Inst Pulawy 56:199-203

Gonkowski S, Rychlik A, Nowicki M, Nieradka R, Bulc M, Całka J (2012b) A population of nesfatin 1-like immunoreactive (LI) cells in the mucosal layer of the canine digestive tract. Res Vet Sci 93: $1119-1121$
Jo SM, Won MH, Cole TB, Jansen MS, Palmiter RD, Danscher G (2000) Zinc-enriched (ZEN) terminals in mouse olfactory bulb. Brain Res 865:227-236

Kaneko M, Noguchi T, Ikegami S, Sakurai T, Kakita A, Toyoshima Y, Kambe T, Yamada M, Inden M, Hara H, Oyanagi K, Inuzuka T, Takahashi H, Hozumi I (2015) Zinc transporters ZnT3 and ZnT6 are downregulated in the spinal cords of patients with sporadic amyotrophic lateral sclerosis. J Neurosci Res 93:370-379

Kasparek MS, Fatima J, Iqbal CW, Duenes JA, Sarr MG (2007) Role of VIP and substance P in NANC innervation in the longitudinal smooth muscle of the rat jejunum - influence of extrinsic denervation. J Surg Res 141:22-30

Li ZS, Furness JB (1998) Immunohistochemical localization of cholinergic markers in putative intrinsic primary afferent neurons of the guinea-pig small intestine. Cell Tissue Res 294:35-43

Molnar P, Nadler JV (2001) Lack of effects of mossy fiber-released zinc on granule cell GABA (a) receptors in the pilocarine model of epilepsy. J Neurophysiol 85:1932-1940

Mourad FH, Barada KA, Bou Rached NA, Khoury CI, Saadé NE, Nassar CF (2006) Inhibitory effect of experimental colitis on fluid absorption in rat jejunum: role of the enteric nervous system, VIP, and nitric oxide. Am J Physiol Gastrointest Liver Physiol 290:G262-G268

Nassar CF, Abdallah LE, Barada KA, Atweh SF, Saadé NF (1995) Effects of intravenous vasoactive intestinal peptide injection on jejunal alanine absorption and gastric acid secretion in rats. Regul Pept 55: 261-267

Palmiter RD, Cole TB, Quaife CJ, Findley SD (1996) ZnT-3, a putative transporter of zinc into synaptic vesicles. Proc Natl Acad Sci U S A 93:14934-14939

Palmiter RD, Huang L (2004) Efflux and compartmentalization of zinc by members of the SLC30 family of solute carriers. Pflugers Arch 447: 744-751

Paulino AS, Palombit K, Cavriani G, Tavares-de-Lima W, Mizuno MS, Marosti AR, da Silva MV, Girotti PA, Liberti EA, Castelucci P (2011) Effects of ischemia and reperfusion on P2X2 receptor expressing neurons of the rat ileum enteric nervous system. Dig Dis Sci 56:2262-2275

Porter AJ, Wattchow DA, Brookes SJ, Schemann M, Costa M (1996) Choline acetyltransferase immunoreactivity in the human small and large intestine. Gastroenterology 111:401-408

Porter AJ, Wattchow DA, Brookes SJ, Costa M (2002) Cholinergic and nitrergic interneurones in the myenteric plexus of the human colon. Gut 51:70-75

Rekawek W, Sobiech P, Gonkowski S, Zarczyńska K, Snarska A, Wasniewski T, Wojtkiewicz J (2015) Distribution and chemical coding patterns of cocaine- and amphetamine-regulated transcript-like immunoreactive (CART-LI) neurons in the enteric nervous system of the porcine stomach cardia. Pol J Vet Sci 18:515-522

Smidt K, Larsen A, Brønden A, Sørensen KS, Nielsen JV, Praetorius J, Martensen PM, Rungby J (2016) The zinc transporter ZNT3 colocalizes with insulin in INS-1E pancreatic beta cells and influences cell survival, insulin secretion capacity, and ZNT8 expression. Biometals 29:287-298

Takeda A (2000) Movement of zinc and its functional significance in the brain. Brain Res Rev 34:137-148

Teixeira AF, Vives P, Krammer HJ, Kühnel W, Wedel T (2001) Structural organization of the enteric nervous system in the cattle esophagus revealed by wholemount immunohistochemistry. Ital J Anat Embryol 106(Suppl 1):313-321

Timmermans JP, Adriaensen D, Cornelissen W, Scheuermann DW (1997) Structural organization and neuropeptide distribution in the mammalian enteric nervous system, with special attention to those components involved in mucosal reflexes. Comp Biochem Physiol A Physiol 118:331-340 
Vasina V, Barbara G, Talamonti L, Stanghellini V, Corinaldesi R, Tonini M, De Ponti F, De Giorgio R (2006) Enteric neuroplasticity evoked by inflammation. Auton Neurosci Bas Clin 126-127:264-272

Wang ZY, Li JY, Danscher G, Dahlström A (2002) Localization of zincenriched neurons in the mouse peripheral sympathetic system. Brain Res 928:165-174

Wang ZY, Danscher G, Dahlstrom A, Li JY (2003) Zinc transporter 3 and zinc ions in the rodent superior cervical ganglion neurons. Neuroscience 120:605-616

Wang ZY, Stoltenberg M, Huang L, Danscher G, Dahlström A, Shi Y, Li JY (2005) Abundant expression of zinc transporters in Bergman glia of mouse cerebellum. Brain Res Bull 64:441-448

Wenzel HJ, Cole TB, Born DE, Schwartzkroin PA, Palmiter RD (1997) Ultrastructural localization of zinc transporter-3 (ZnT3) to synaptic vesicle membranes within mossy fiber boutons in the hippocampus of mouse and monkey. Proc Natl Acad Sci U S A 94:12676-12681
Wojtkiewicz J, Równiak M, Crayton R, Majewski M, Gonkowski S (2012a) Chemical coding of zinc-enriched neurons in the intramural ganglia of the porcine jejunum. Cell Tissue Res 350:215-223

Wojtkiewicz J, Gonkowski S, Równiak M, Crayton R, Majewski M, Jałyński M (2012b) Neurochemical characterization of zinc transporter 3-like immunoreactive $(\mathrm{ZnT} 3(+))$ neurons in the intramural ganglia of the porcine duodenum. J Mol Neurosci 48:766-776

Wojtkiewicz J, RowniakM CR, Gonkowski S, Robak A, Zalecki M, Majewski M, Klimaschewski L (2013) Axotomy-induced changes in the chemical coding pattern of colon projecting calbindin-positive neurons in the inferior mesenteric ganglia of the pig. J Mol Neurosci 51:99-108

Zacharko-Siembida A, Arciszewski MB (2014) Immunoreactivity to cocaine- and amphetamine-regulated transcript in the enteric nervous system of the pig and wild boar stomach. Anat Histol Embryol 43(1):48-55 